\title{
Transcriptomic Response of Saccharomyces cerevisiae during Fermentation under Oleic Acid and Ergosterol Depletion
}

\author{
Giacomo Zara ${ }^{1, *}$, Hennie J. J. van Vuuren ${ }^{2}$, Ilaria Mannazzu ${ }^{1}$, Severino Zara ${ }^{1}$ and \\ Marilena Budroni ${ }^{1}$ \\ 1 Department of Agriculture, University of Sassari, 07100 Sassari, Italy \\ 2 Wine Research Centre, The University of British Columbia, Vancouver, BC V6T 1Z4, Canada \\ * Correspondence: gzara@uniss.it; Tel.: +39-079-229286
}

Received: 8 June 2019; Accepted: 1 July 2019; Published: 3 July 2019

check for updates

\begin{abstract}
Under anaerobic/hypoxic conditions, Saccharomyces cerevisiae relies on external lipid supplements to modulate membrane lipid fraction in response to different stresses. Here, transcriptomic responses of two $S$. cerevisiae wine strains were evaluated during hypoxic fermentation of a synthetic must with/without ergosterol and oleic acid supplementation. In the absence of lipids, the two strains, namely EC1118 and M25, showed different behaviour, with M25 significantly decreasing its fermentation rate from the $72 \mathrm{~h}$ after inoculum. At this time point, the whole genome transcriptomic analysis revealed common and strain-specific responses to the lack of lipid supplementation. Common responses included the upregulation of the genes involved in ergosterol biosynthesis, as well as the seripauperin and the heat shock protein multigene families. In addition, the upregulation of the aerobic isoforms of genes involved in mitochondrial electron transport is compatible with the previously observed accumulation of reactive oxygen species in the two strains during growth in absence of lipids. Considering the strain-specific responses, M25 downregulated the transcription of genes involved in glucose transport, methionine biosynthesis and of those encoding mannoproteins required for adaptation to low temperatures and hypoxia. The identification of these pathways, which are presumably involved in yeast resistance to stresses, will assist industrial strain selection.
\end{abstract}

Keywords: wine fermentation; ergosterol; oxidative stress; TIR/TIP; methionine biosynthesis

\section{Introduction}

During white wine fermentation, S. cerevisiae is subjected to (i) high osmotic pressure, (ii) limited nitrogen concentrations, (iii) prolonged hypoxic/anaerobic conditions, (iv) the presence of chemical preservatives (sulphites), (v) increasing ethanol concentrations, and (vi) low temperatures. Thus, white winemaking represents an interesting process to understand yeast response and adaptation to many different stresses occurring during industrial processes. Different mechanisms permitting yeast to grow in hostile and stressful environments have been documented so far. Upon osmotic stress, the High Osmolarity Glycerol (HOG) pathway governs the production of glycerol as a compatible solute [1]. The Target of Rapamycin (TOR) pathway allows yeast cells to adapt to nitrogen limitation conditions by triggering morphological transitions such as pseudohyphal growth and biofilm formation [2,3]. Reactive oxygen species (ROS) generated during wine fermentation trigger the production of proteins needed to protect the cells against oxidative stress [4,5]. Temperature changes activate the production of heat shock proteins (HSPs) through the Heat Shock Response pathway [6,7]. HSPs, involved in folding, stabilization or degradation of protein aggregates, are also controlled by the General Stress Response pathway [5]. This pathway overlaps with the other stress responses. 
Modification of the membrane lipid composition is another cellular response elicited by different stress factors which confers so called "cross-protection", i.e., the "increased resistance to multiple stresses conferred by sublethal doses of one stress condition" [8]. Henderson and Block [9] found that bioethanol production and maximum yeast cell density were highly correlated with yeast cell lipid composition Indeed, changes in the relative abundance of saturated fatty acids (SFAs), unsaturated fatty acids (UFAs), and ergosterol allow yeast cells to counteract variations in membrane fluidity and permeability, that can severely impair the activities of transmembrane proteins [10]. S. cerevisiae derives cell lipids via the assimilation of external nutritional supplies and/or the activation of lipid biosynthesis. During winemaking, the biosynthesis of unsaturated fatty acids and ergosterol is impaired, as oxygen is required to desaturated SFA and to complete the oxygen-dependent steps of sterol biosynthesis. In these conditions, wine yeasts can assimilate exogenous sterols and UFAs [11,12]. However, it has been observed that some oenological practices, such as excessive must clarification and a short time of contact between grape solids and juice, may significantly reduce the levels of UFA and sterols in must [13]. Thus, in absence of appropriate lipid supplementation, yeast adaptation to the stressful conditions encountered during winemaking, such as high osmotic pressure, prolonged hypoxic/anaerobic conditions, high ethanol concentrations and low temperatures, strictly relies on yeast ability to make optimal use of the dissolved oxygen in the first hours of fermentation [14].

Our previous researches have shown that during fermentation in absence of lipid supplementation, wine strains of $S$. cerevisiae showed different fermentative abilities that were related to their ability to scavenge ROS [4] and activate the transcription of key genes in lipid metabolism [15]. In this context, the aim of this work was to further elucidate the mechanisms involved in S. cerevisiae adaptation to fermentation in hypoxic conditions in absence of lipid supplementation. To this end, the genome-wide response of two S. cerevisiae strains with different susceptibility to stuck/sluggish fermentation was determined by transcriptomic analysis in two media characterized by the presence and absence of lipid supplementation. This comparative approach allowed the identification of candidate yeast genes commonly regulated in the two strains and specifically associated with resistance to the lack of lipid supplementation.

\section{Materials and Methods}

\subsection{Yeast Strains and Growth Conditions}

S. cerevisiae strains used in this study were the industrial wine strain EC1118 (Lalvin, Canada) and the wild-type wine strain M25 belonging to the culture collection of the Department of Agricultural science, University of Sassari (Sassari, Italy). EC1118 was rehydrated according to the manufacturer's instructions. Yeast strains were precultured at $25^{\circ} \mathrm{C}$ for $24 \mathrm{~h}$ in a rotary shaker $(300 \mathrm{rpm})$ in flasks containing synthetic juice (SJ) prepared as described in [16] and containing glucose $200 \mathrm{~g} / \mathrm{L}$, tartaric acid $2 \mathrm{~g} / \mathrm{L}$, malic acid $2 \mathrm{~g} / \mathrm{L}$, citric acid $0.2 \mathrm{~g} / \mathrm{L}, \mathrm{YNB}$ w/o amino acids and w/o ammonium sulphate $1.7 \mathrm{~g} / \mathrm{L}$, ammonium sulphate $2 \mathrm{~g} / \mathrm{L}$. $\mathrm{pH}$ was adjusted to 3.3 with $\mathrm{KOH}$. Cells from precultures were inoculated to the final concentration of $1 \times 10^{6} \mathrm{cell} / \mathrm{mL}$ in $500 \mathrm{~mL}$ flasks equipped with glass capillary stoppers and containing $350 \mathrm{~mL}$ of liquid media. The media used for bench-scale fermentations were SJ and ergosterol/oleic acid supplemented SJ (FSJ: SJ with $15 \mathrm{mg} / \mathrm{L}$ ergosterol and $20 \mathrm{mg} / \mathrm{L}$ oleic acid). Fermentations were carried out in triplicate in static at $20^{\circ} \mathrm{C}$ for 30 days and monitored by measuring weight loss, optical density (A600) and glucose concentration (enzymatic kit Roche Molecular Biochemicals, Laval, QC, Canada).

\subsection{RNA Extraction and Microarray Analysis}

Yeast cells growing in SJ and FSJ were collected after $72 \mathrm{~h}$ from the inoculum, rapidly harvested, washed and stored at $-80^{\circ} \mathrm{C}$ until RNA extraction. Total RNA was extracted using the hot-phenol method [17]. From total RNA, mRNA was isolated according to [18]. Poly(A)+ RNA purification, amplification, labelling, and cRNA fragmentation were carried out as described previously [19]. 
Twelve oligonucleotide yeast genome arrays (YGS98, Affymetrix, Santa Clara, CA, USA) were used as targets for hybridization. Hybridization, washing, staining and scanning of yeast arrays were done as described by the manufacturer (Eukaryotic Arrays GeneChip Expression Analysis and Technical Manual, Affymetrix, Santa Clara, CA, USA). Washing and staining were carried out using the EukGE-WS2v3 fluidics protocol of the Affymetrix MASv5.0 software (Affymetrix, Santa Clara, CA, USA). Scanning of the arrays was done on an Agilent G2500A GeneArray Scanner (Agilent Technologies, Palo Alto, CA, USA). The data discussed in this publication have been deposited in NCBI's Gene Expression Omnibus [20] and are accessible through GEO Series accession number GSE130016 (https://www.ncbi.nlm.nih.gov/geo/query/acc.cgi?acc=GSE130016) (access on 18 April 2019).

\subsection{Data Analysis}

Preliminary analysis of gene expression data was carried out using Affymetrix Microarray Suite v5.0 (MASv5.0). To determine absolute call a statistical algorithm based on the Wilcoxon signed-rank test was used. The detection $p$-value was set at $\leq 0.05$ for genes with a present call. For each condition, only the genes with the same change call in the three replicated experiments were included. The effect of the medium (first independent variable with two levels) and of the yeast strain used (second independent variable with two levels) on the transcription level of each gene (dependent variable) was evaluated by fitting a linear model. A gene was considered to show significant differential expression if the $p$-value (adjusted for false discovery rate (FDR) using the Benjamini and Hochberg method [21]) was $<0.05$. Significant genes were functionally annotated using the high-throughput enrichment tool DAVID v6.8 [22]. Transcription factor analysis was carried out using YEASTRACT [23].

\section{Results}

\subsection{Fermentation Profiles in Absence of Lipid Supplementation.}

The ability of yeast strains to adapt to the lack of lipid supplementation was tested by growing two wine strains of $S$. cerevisiae in synthetic juice lacking lipids (SJ). As a control condition, the same strains were inoculated in SJ enriched with oleic acid and ergosterol (FSJ). While EC1118 was able to complete the fermentation in the two media (Figure 1), M25 completed the fermentation in FSJ but underwent a stuck/sluggish fermentation in SJ (Figure 2). In particular, the fermentative behavior of M25 was significantly lower $(p<0.05)$ in SJ than in FSJ starting from $72 \mathrm{~h}$ from the inoculum.

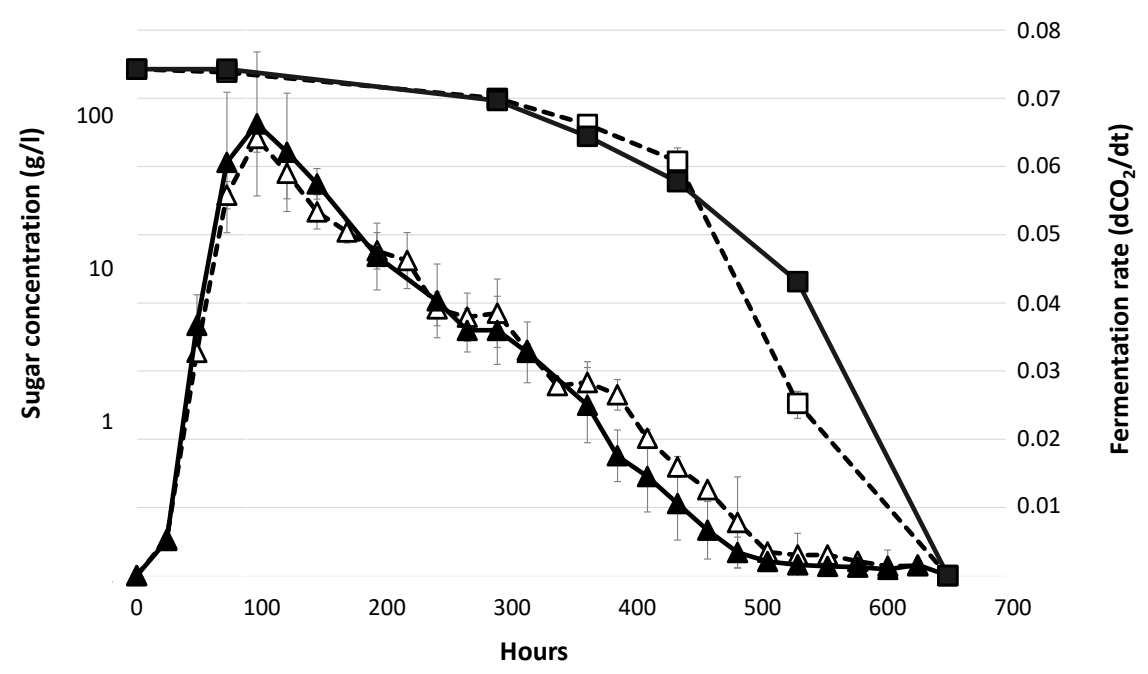

Figure 1. Fermentation kinetics and sugar consumption of EC1118 during growth in FSJ (straight lines) and SJ (dotted lines). Black triangles: fermentation rate in FSJ; white triangles: fermentation rate in SJ; black squares: residual glucose in FSJ; white squares: residual glucose in SJ. Data are means \pm standard deviation of three independent biological replicates. 


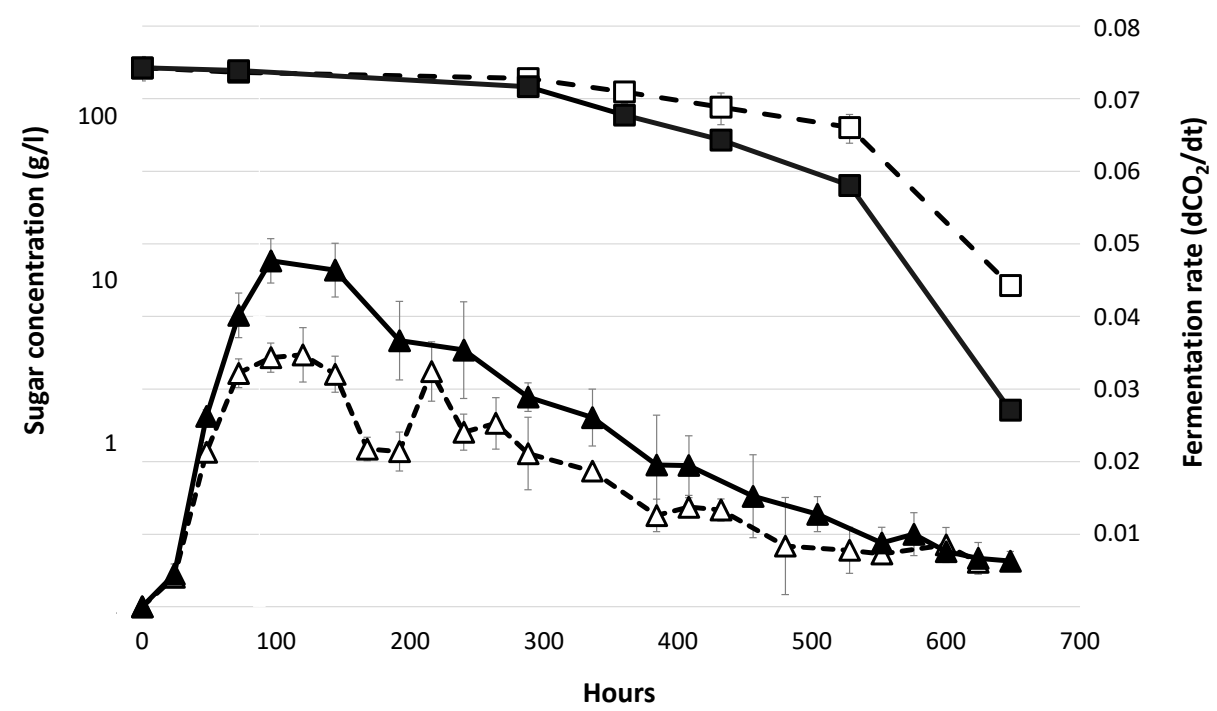

Figure 2. Fermentation kinetics and sugar consumption of M25 during growth in FSJ (straight lines) and SJ (dotted lines). Black triangles: fermentation rate in FSJ; white triangles: fermentation rate in SJ; black squares: residual glucose in FSJ; white squares: residual glucose in SJ. Data are means \pm standard deviation of three independent biological replicates.

The reduced fermentative performances were associated with significant lower growth rates and maximum population sizes in M25 growing in SJ than in all the other strain/medium combinations (Table 1).

Table 1. Parameters for the logistic equation fitted on cell viability data of M25 and EC1118 strains growing in absence (SJ) and in presence (FSJ) of oleic acid and ergosterol supplementation.

\begin{tabular}{|c|c|c|c|c|}
\hline Sample & Medium & $\begin{array}{l}\text { Maximum Population Size } \\
\qquad\left(10^{7} \mathrm{cell} / \mathrm{mL}\right)\end{array}$ & $\begin{array}{l}\text { Growth Rate } \\
\qquad\left(h^{-1}\right)\end{array}$ & Area under Curve \\
\hline \multirow{2}{*}{ M25 } & SJ & $1.230^{\mathrm{a}} \pm 0.16$ & $0.094^{\mathrm{a}} \pm 0.05$ & $236.09^{a} \pm 12.01$ \\
\hline & FSJ & $1.406^{\mathrm{c}} \pm 0.22$ & $0.156^{b} \pm 0.11$ & $275.02^{b} \pm 20.12$ \\
\hline \multirow{2}{*}{ EC1118 } & SJ & $1.366^{b} \pm 0.25$ & $0.351^{\mathrm{c}} \pm 0.29$ & $267.91^{b} \pm 19.84$ \\
\hline & FSJ & $1.383^{b} \pm 0.18$ & $0.298^{c} \pm 0.25$ & $270.73^{b} \pm 15.71$ \\
\hline
\end{tabular}

a, b,c Superscript letters in the same column indicate significant groups as determined by ANOVA followed by Tukey-HSD test $(p<0.05)$.

\subsection{Transcriptomic Response during Fermentation in Absence of Lipid Supplementation}

By fitting a linear model to the transcriptional data, it was possible to identify the genes whose expression changed in the two strains as a response to the absence of lipid supplementation. Of the 4176 ORF analyzed, 544 were differentially expressed in SJ (adjusted $p$-value of the medium effect $<0.05$ ) (Table S1). Of these, $213 \mathrm{ORFs}$ were commonly regulated regardless of the strain background (strain effect $p$-value $>0.0330$ which corresponds to FDR $>0.05$ ). The remaining 331 ORFs were differentially expressed in M25 and EC1118 (strain effect $p$-value $<0.0330$ )

To gain insight into the common metabolic pathways involved in the response of yeast cells to the lack of lipid supplementation, the 213 ORFs showing the same regulation in the two strains were condensed into Annotation Clusters (AC) using the DAVID web tool (Table 2). 
Table 2. Annotation clusters of M25 and EC1118 ORFs showing significant medium and not significant strain effect.

\begin{tabular}{|c|c|c|c|c|}
\hline \multicolumn{5}{|c|}{ Functional Groups Upregulated in SJ } \\
\hline Annotation Cluster 1 & Enrichment Score: 9.36 & Count & $p_{-}$Value & Benjamini \\
\hline GOTERM_BP_DIRECT & ergosterol biosynthetic process & 13 & $3.9 \times 10^{-15}$ & $5.4 \times 10^{-13}$ \\
\hline UP_KEYWORDS & Sterol biosynthesis & 12 & $1.3 \times 10^{-13}$ & $1.7 \times 10^{-11}$ \\
\hline KEGG_PATHWAY & Steroid biosynthesis & 8 & $8.2 \times 10^{-9}$ & $2.5 \times 10^{-7}$ \\
\hline UP_KEYWORDS & Lipid biosynthesis & 13 & $7.6 \times 10^{-8}$ & $3.4 \times 10^{-6}$ \\
\hline GOTERM_BP_DIRECT & lipid metabolic process & 14 & $7.0 \times 10^{-6}$ & $2.7 \times 10^{-4}$ \\
\hline UP_KEYWORDS & Lipid metabolism & 14 & $8.3 \times 10^{-6}$ & $2.8 \times 10^{-4}$ \\
\hline Annotation Cluster 2 & Enrichment Score: 6.41 & Count & $p \_$Value & Benjamini \\
\hline GOTERM_BP_DIRECT & oxidation-reduction process & 24 & $1.6 \times 10^{-7}$ & $7.0 \times 10^{-6}$ \\
\hline UP_KEYWORDS & Oxidoreductase & 17 & $8.5 \times 10^{-5}$ & $1.6 \times 10^{-3}$ \\
\hline GOTERM_MF_DIRECT & oxidoreductase activity & 17 & $2.2 \times 10^{-4}$ & $1.3 \times 10^{-2}$ \\
\hline Annotation Cluster 3 & Enrichment Score: 3.51 & Count & $p_{-}$Value & Benjamini \\
\hline GOTERM_BP_DIRECT & response to stress & 11 & $1.0 \times 10^{-8}$ & $5.4 \times 10^{-7}$ \\
\hline GOTERM_MF_DIRECT & structural constituent of cell wall & 9 & $2.5 \times 10^{-6}$ & $4.6 \times 10^{-4}$ \\
\hline GOTERM_BP_DIRECT & fungal-type cell wall organization & 10 & $1.6 \times 10^{-3}$ & $5.2 \times 10^{-2}$ \\
\hline GOTERM_CC_DIRECT & fungal-type cell wall & 9 & $1.8 \times 10^{-3}$ & $3.3 \times 10^{-2}$ \\
\hline Annotation Cluster 4 & Enrichment Score: 3 & Count & $p \_$Value & Benjamini \\
\hline UP_KEYWORDS & Heme & 7 & $7.4 \times 10^{-5}$ & $2.0 \times 10^{-3}$ \\
\hline GOTERM_MF_DIRECT & heme binding & 6 & $2.1 \times 10^{-4}$ & $1.9 \times 10^{-2}$ \\
\hline Annotation Cluster 5 & Enrichment Score: 2.44 & Count & $p_{-}$Value & Benjamini \\
\hline UP_KEYWORDS & \multirow{3}{*}{$\begin{array}{l}\text { Electron transport } \\
\text { mitochondrial electron transport, } \\
\text { ubiquinol to cytochrome c } \\
\text { respiratory chain }\end{array}$} & 7 & $4.5 \times 10^{-4}$ & $7.5 \times 10^{-3}$ \\
\hline GOTERM_BP_DIRECT & & 4 & $1.8 \times 10^{-3}$ & $5.3 \times 10^{-2}$ \\
\hline GOTERM_CC_DIRECT & & 4 & $3.5 \times 10^{-3}$ & $5.3 \times 10^{-2}$ \\
\hline \multicolumn{5}{|c|}{ Functional Groups Downregulated in SJ } \\
\hline Annotation Cluster 6 & Enrichment Score: 2.46 & Count & $p_{-}$Value & Benjamini \\
\hline GOTERM_BP_DIRECT & cytoplasmic translation & 11 & $2.5 \times 10^{-4}$ & $6.7 \times 10^{-2}$ \\
\hline GOTERM_CC_DIRECT & intracellular ribonucleoprotein complex & 14 & $4.5 \times 10^{-4}$ & $4.2 \times 10^{-2}$ \\
\hline UP_KEYWORDS & Ribonucleoprotein & 14 & $5.0 \times 10^{-4}$ & $6.3 \times 10^{-2}$ \\
\hline GOTERM_CC_DIRECT & cytosolic large ribosomal subunit & 8 & $9.0 \times 10^{-4}$ & $4.2 \times 10^{-2}$ \\
\hline Annotation Cluster 7 & Enrichment Score: 2.21 & Count & $p_{-}$Value & Benjamini \\
\hline UP_KEYWORDS & Purine biosynthesis & 4 & $2.2 \times 10^{-3}$ & $5.6 \times 10^{-2}$ \\
\hline GOTERM_BP_DIRECT & purine nucleotide biosynthetic process & 4 & $2.4 \times 10^{-3}$ & $2.8 \times 10^{-1}$ \\
\hline
\end{tabular}

Lack of lipid nutrients induced a significant upregulation of the ORFs involved in ergosterol biosynthesis (Figure 3) and in oxidation-reduction processes, particularly those involved in the mitochondrial electron transport such as COX5A and CYC1.

The stress generated by the absence of lipids induced the upregulation of the ORFs associated with the cell-wall: the seripauperins PAU3, PAU4, PAU5, PAU10, PAU14, PAU15, PAU20, PAU23 as well as HSP12. In addition, other HSP genes were upregulated in SJ, particularly HSP104, HSP12, HSP26, HSP31 and HSP60. On the contrary, ORFs involved in cytoplasmatic translation (AC 6) and in purine biosynthesis (AC 7) were downregulated, suggesting reduced protein biosynthesis in SJ.

Up- and down-regulated ORFs were further analyzed to identify potential transcription factors involved in the adaptation to the absence of lipid supplementation. Enrichment analysis carried out using the YEASTRACT database showed that Sfp1p is associated with $85.37 \%$ and $83.15 \%$ of the upregulated and downregulated ORFs, respectively (Table 3). Transcription factors Upc2p, Ecm22p, Hap1p, Mot3p, Rox1p were specifically associated with the upregulated ORFs. In accordance, genes encoding for some of those transcription factors were upregulated in SJ as well: HAP4 $=0.88 \log 2$ 
SJ/FSJ, MOT3 = $1.53 \log 2 \mathrm{SJ} / \mathrm{FSJ}$, ROX1 = $1.63 \log 2 \mathrm{SJ} / \mathrm{FSJ}$. The ORFs showing a repression in absence of lipid supplementation were regulated by the transcription factors Gcn4p and Yap1p.

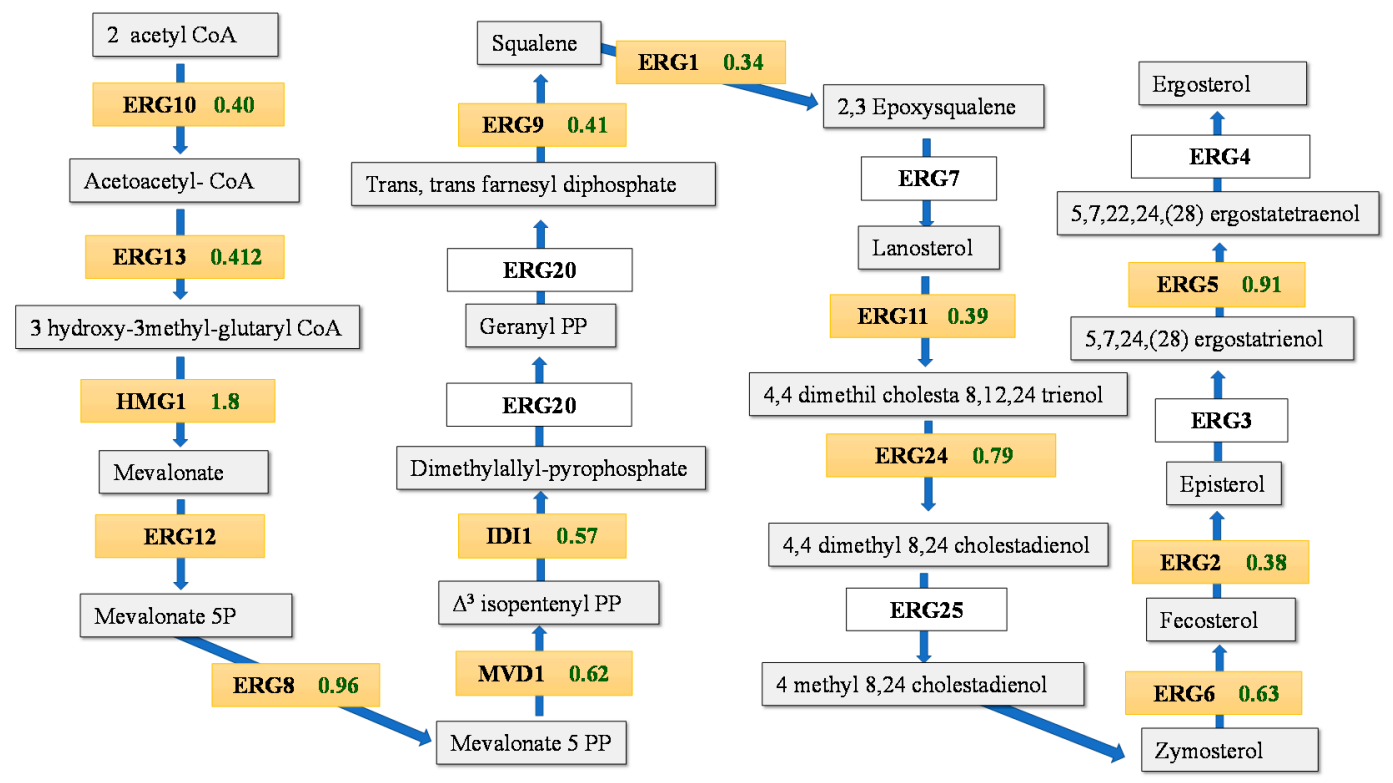

Figure 3. Ergosterol biosynthetic pathway. ORFs showing significant upregulation in SJ with respect to FSJ in EC1118 and M25 are highlighted in yellow. Green numbers indicate mean log2 ratio (SJ/FSJ).

Table 3. Transcription factors associated with upregulated and downregulated ORFs in SJ with respect to FSJ.

\begin{tabular}{cccc}
\hline Upregulated ORFs & \multicolumn{3}{c}{} \\
\hline Transcription Factors & $\%$ in user set & $\%$ in Yeastract & $p$-value \\
Sfp1p & $85.37 \%$ & $2.42 \%$ & $4.45 \times 10^{-10}$ \\
Hap1p & $39.84 \%$ & $14.08 \%$ & $1.03 \times 10^{-15}$ \\
Rox1p & $30.08 \%$ & $4.10 \%$ & $6.82 \times 10^{-8}$ \\
Mot3p & $26.02 \%$ & $5.43 \%$ & $5.86 \times 10^{-10}$ \\
Ecm22p & $23.58 \%$ & $5.45 \%$ & $3.75 \times 10^{-9}$ \\
Upc2p & $21.95 \%$ & $8.49 \%$ & $3.80 \times 10^{-13}$ \\
\hline Downregulated ORFs & \multicolumn{3}{|}{} \\
\hline Transcription Factors & $\%$ in user set & $\%$ in Yeastract & $1.17 \times 10^{-6}$ \\
Sfp1p & $83.15 \%$ & $1.71 \%$ & $6.025 \times 10^{-7}$ \\
Yap1p & $73.03 \%$ & $1.88 \%$ & $8.73 \times 10^{-9}$ \\
Gcn4p & $70.79 \%$ & $2.10 \%$ & \\
\hline
\end{tabular}

3.3. Differences in the Transcriptomic Response of M25 and EC1118 during Growth in Absence of Oleic Acid and Ergosterol Supplementation

Considering that M25 and EC1118 showed a different fermentative behavior in SJ, differences in the transcriptional response of the two strains could provide information about the successful adaptation of EC1118 to the absence of lipid nutrients in the fermentation medium. Thus, the 331 ORFs showing a significant medium and strain effect were clustered according to their functional annotations (Table 4). Expression values of genes differentially expressed in M25 and EC1118 and included in the biological process GO:0009086 "methionine biosynthetic process", in the cellular component GO:0009277 "fungal-type cell wall" and in the cellular component GO:0005887 "integral component of plasma membrane" are reported in Figures 4-6 respectively. 
Table 4. Annotation clusters of ORFs differentially expressed in M25 and EC1118 in response to fermentation in absence of oleic acid and ergosterol.

\begin{tabular}{|c|c|c|c|c|}
\hline Annotation Cluster 1 & Enrichment Score: 4.43 & Count & $p_{-}$Value & Benjamini \\
\hline GOTERM_BP_DIRECT & cellular amino acid biosynthetic process & 23 & $7.5 \times 10^{-9}$ & $2.6 \times 10^{-6}$ \\
\hline GOTERM_BP_DIRECT & methionine biosynthetic process & 11 & $5.4 \times 10^{-7}$ & $1.2 \times 10^{-4}$ \\
\hline UP_KEYWORDS & Cysteine biosynthesis & 6 & $1.9 \times 10^{-4}$ & $1.2 \times 10^{-2}$ \\
\hline KEGG_PATHWAY & Sulfur metabolism & 5 & $4.7 \times 10^{-3}$ & $6.1 \times 10^{-2}$ \\
\hline Annotation Cluster 2 & Enrichment Score: 3.7 & Count & $p_{-}$Value & Benjamini \\
\hline INTERPRO & Stress-induced protein SRP1/TIP1 & 16 & $6.4 \times 10^{-11}$ & $3.9 \times 10^{-8}$ \\
\hline GOTERM_BP_DIRECT & response to stress & 17 & $7.3 \times 10^{-10}$ & $5.1 \times 10^{-7}$ \\
\hline GOTERM_MF_DIRECT & structural constituent of cell wall & 17 & $1.3 \times 10^{-9}$ & $5.4 \times 10^{-7}$ \\
\hline GOTERM_CC_DIRECT & fungal-type cell wall & 24 & $2.4 \times 10^{-8}$ & $4.3 \times 10^{-6}$ \\
\hline GOTERM_BP_DIRECT & fungal-type cell wall organization & 23 & $6.3 \times 10^{-6}$ & $1.1 \times 10^{-3}$ \\
\hline UP_KEYWORDS & Cell wall & 13 & $2.1 \times 10^{-4}$ & $1.1 \times 10^{-2}$ \\
\hline GOTERM_CC_DIRECT & cell wall & 13 & $2.3 \times 10^{-4}$ & $2.0 \times 10^{-2}$ \\
\hline Annotation Cluster 3 & Enrichment Score: 2.66 & Count & $p_{-}$Value & Benjamini \\
\hline UP_SEQ_FEATURE & transit peptide:Mitochondrion & 34 & $5.8 \times 10^{-4}$ & $1.2 \times 10^{-1}$ \\
\hline UP_KEYWORDS & Mitochondrion & 62 & $2.3 \times 10^{-3}$ & $4.2 \times 10^{-2}$ \\
\hline Annotation Cluster 7 & Enrichment Score: 2.25 & Count & $p_{-}$Value & Benjamini \\
\hline UP_KEYWORDS & Arginine biosynthesis & 5 & $9.7 \times 10^{-4}$ & $2.4 \times 10^{-2}$ \\
\hline Annotation Cluster 8 & Enrichment Score: 1.79 & Count & $p_{-}$Value & Benjamini \\
\hline GOTERM_CC_DIRECT & integral component of plasma membrane & 18 & $2.8 \times 10^{-4}$ & $1.6 \times 10^{-2}$ \\
\hline
\end{tabular}

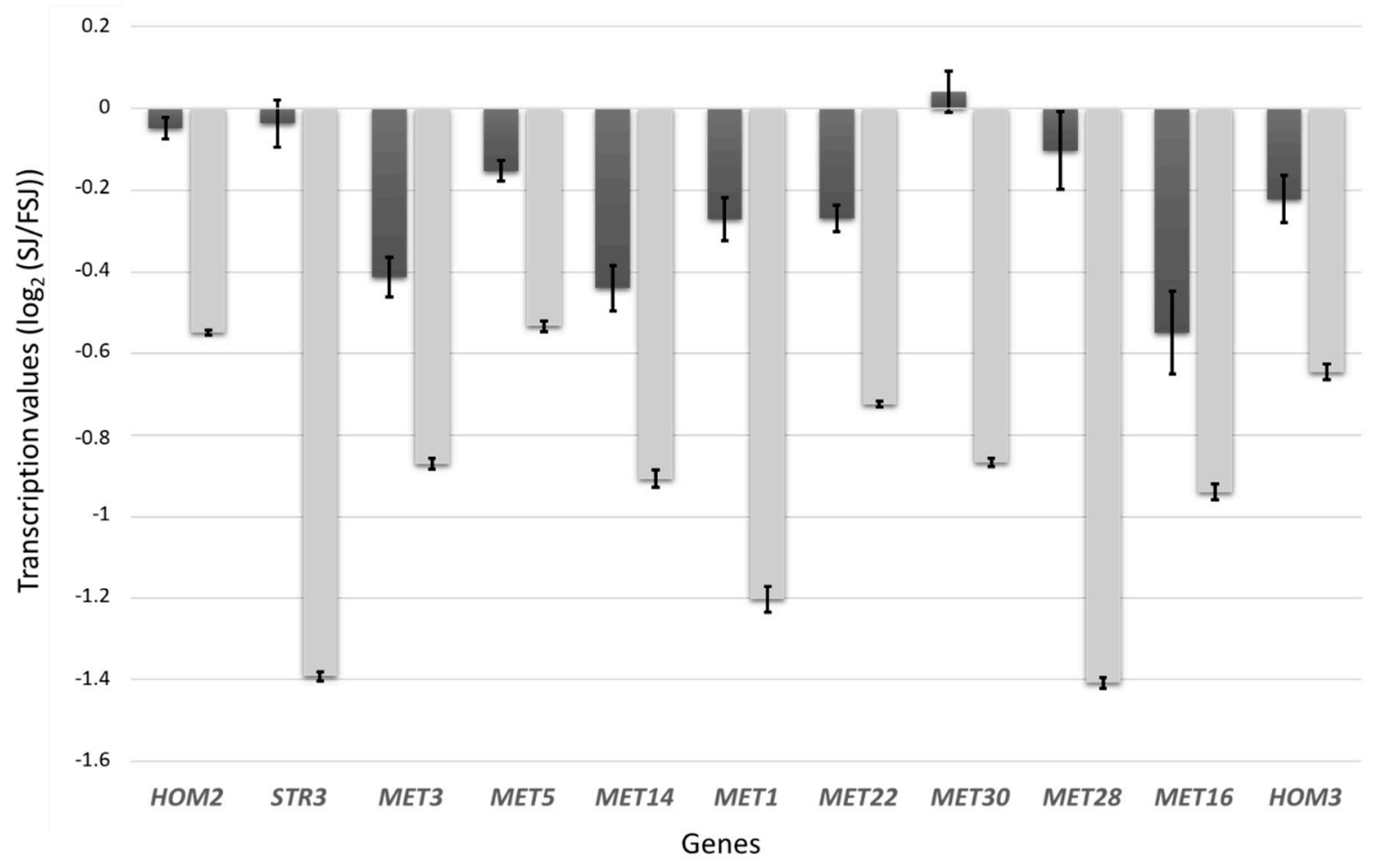

Figure 4. Transcription values of genes differentially expressed in EC1118 (black bars) and M25 (gray bars) in the functional category GO:0009086 "methionine biosynthetic process". Data are mean log2 ratio $(\mathrm{SJ} / \mathrm{FSJ}) \pm$ standard deviation of three independent biological replicates. 


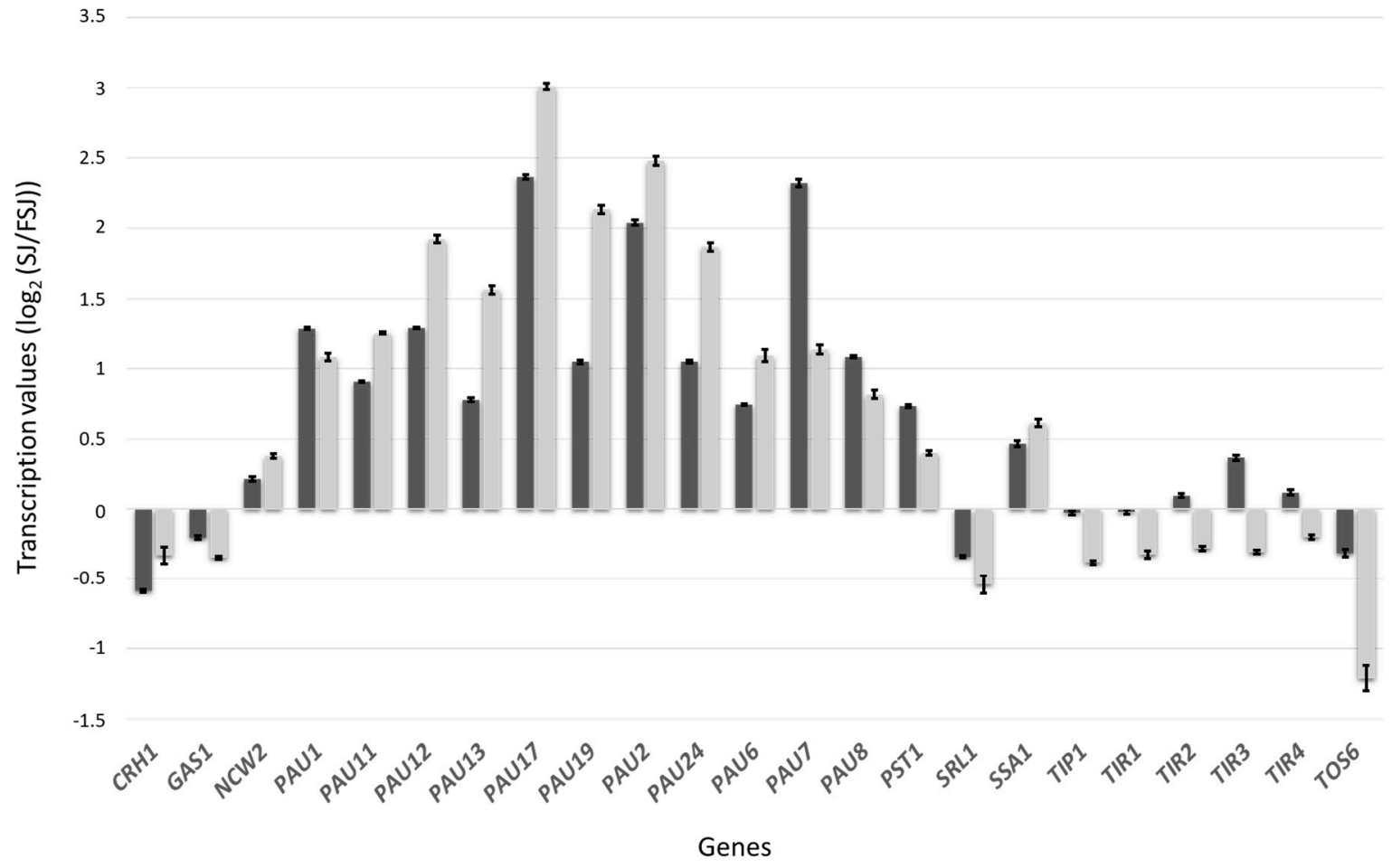

Figure 5. Transcription values of genes differentially expressed in EC1118 (black bars) and M25 (gray bars) in the functional category GO:0009277 "fungal-type cell wall". Data are mean log2 ratio $(\mathrm{SJ} / \mathrm{FSJ}) \pm$ standard deviation of three independent biological replicates.

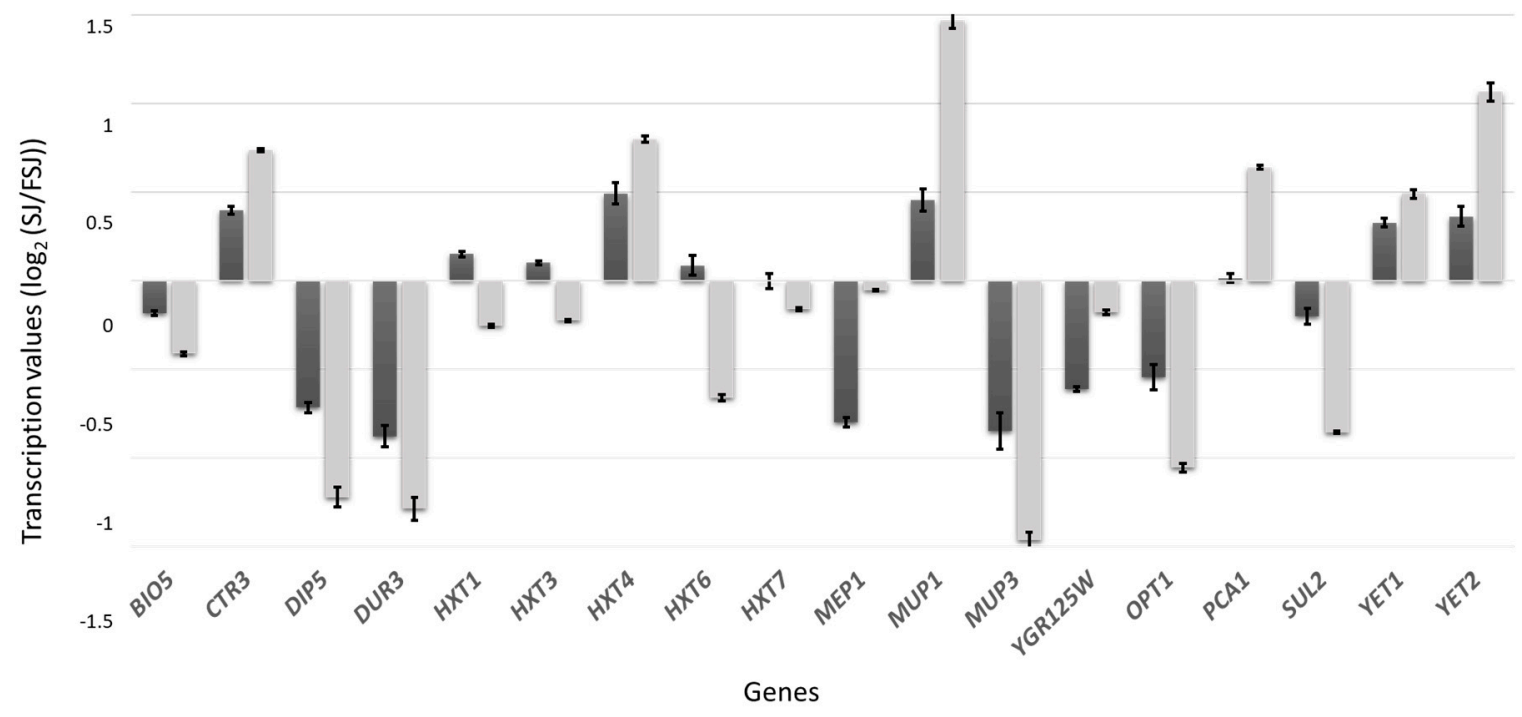

Figure 6. Transcription values of genes differentially expressed in EC1118 (black bars) and M25 (gray bars) in the functional category GO:0005887 "integral component of plasma membrane". Data are mean $\log 2$ ratio $(\mathrm{SJ} / \mathrm{FSJ}) \pm$ standard deviation of three independent biological replicates.

\section{Discussion}

During winemaking, yeasts modulate membrane fluidity in response to stressful conditions such as high ethanol content, low temperatures, hyperosmosis, etc. This modification, which requires changes in the UFA/SFA ratio as well as in the ergosterol content, is severely affected by prolonged hypoxic conditions [10]. In this context, the aim of this work was to elucidate the transcriptomic response of yeast during fermentation in absence of lipid supplementation. To do this, we firstly 
identified the conditions and the phase of growth in which to cultivate and collect cells of two S. cerevisiae strains, namely EC1118 and M25.

In particular, we used two synthetic musts characterized by the absence (SJ) and the presence (FSJ) of ergosterol and oleic acid. We previously found that the amounts of acetic acid produced by EC1118 and M25 in SJ increased with respect to FSJ [24]. In more detail, acetic acid increased from $1.03 \mathrm{~g} / \mathrm{L}$ to $1.37 \mathrm{~g} / \mathrm{L}$ and from $0.91 \mathrm{~g} / \mathrm{L}$ to $1.13 \mathrm{~g} / \mathrm{L}$ in EC1118 and M25, respectively. Considering that higher acetic acid concentrations are indicative of an impaired lipid biosynthesis [25], SJ appeared the adequate medium to evaluate the yeast response to the specific stress induced by lack of lipids. In the chosen conditions the two strains showed a different susceptibility to undergo stuck/sluggish fermentation, in accordance with previous observations $[4,15,26]$. In particular, EC1118 showed identical fermentation profiles in the two media, while M25 was unable to complete the fermentation in SJ. It has been observed that high nitrogen content and low lipid supplementation, such as in SJ, exerted a negative effect on yeast cell viability [27]. Notably, ammonium was the most effective trigger of cell death at the end of fermentation [27]. Thus, the fermentative behavior of M25 and EC1118 in SJ could be related to differences in cell viability of the two strains in the late stationary phase. However, we found that M25 had higher cell viability than EC1118 after $480 \mathrm{~h}$ from the inoculum in SJ $\left(2.7 \pm 0.5 \times 10^{7} \mathrm{UFC} / \mathrm{mL}\right.$ in M25 vs $7.3 \pm 0.7 \times 10^{6} \mathrm{UFC} / \mathrm{mL}$ in EC1118). Thus, cell viability at the end of the stationary phase did not correctly indicate the outcome of the fermentation. Bisson [25] suggested that the number of cells in the exponential phase is an important parameter in determining the fermentation outcome. Accordingly, we found that the fermentation rate of M25 was related to lower cell populations in SJ as compared to FSJ during the first days of fermentation. Thus, in consideration of the observation that the reduction of the fermentation rate was statistically significant from the $72 \mathrm{~h}$ after the inoculum, cells of EC1118 and M25 were sampled in SJ and FSJ at this specific time point for the genome-wide transcriptome analysis.

The implementation of a full factorial design $(2 \times 2)$ allowed us to identify common as well as strain-specific responses to the lack of lipid supplementation. The most significant common response to the growth in SJ was the strong induction of the transcription of genes associated with ergosterol biosynthesis. This behavior was expected considering that $E R G$ genes are transcriptionally activated in response to ergosterol depletion [28]. During hypoxic growth, low ergosterol levels cause an increase in membrane fluidity thus activating the HOG pathway. This pathway induces the activation and accumulation of the transcription factor Upc2p (UPC2 $=1.026 \log 2 \mathrm{SJ} /$ FSJ; this work) [29]. Upc2p binds the sterol regulatory element (SRE) in the promoter of many ERG genes activating their transcription [30]. In addition, Upc2p controls the expression of two sterol transporters, encoded by AUS1 (0.90 log2 SJ/FSJ) and PDR11 (0.74 log2 SJ/FSJ), allowing yeast cells to take up sterols form the medium when biosynthesis is compromised [31,32]. Consistent with the observation that ergosterol levels play a role in oxygen sensing and signaling [33], Upc2p also regulates the expression of hypoxic genes particularly the PAU genes and those involved in mannoprotein and heme synthesis [34,35]. Accordingly, we measured a significant induction of 19 PAU genes in the medium lacking lipid supplementation. The PAU genes are the largest gene family in S. cerevisiae comprising 24 members that encode proteins involved in the remodeling of cell wall [36]. PAU genes play an important role during alcoholic fermentation as they are highly upregulated during fermentation in response to wine-making stress and hypoxia [35,37-39]. Nineteen copies of PAU genes are located in subtelomeric regions, and five copies are found in internal regions. It has been suggested that the subtelomeric PAU genes are more weakly inducible than the internal ones [39]. Our results, however, showed that 18 out of the 19 PAU genes upregulated in SJ were located in the subtelomeric regions, confirming what already observed for PAU20 by Luo and van Vuuren [35]. Other hypoxic genes significantly induced in M25 and EC1118 in response to the lack of lipid were involved in heme synthesis, particularly HEM1 (0.12 log2 SJ/FSJ), HEM2 (0.73 log2 SJ/FSJ), HEM12 (0.14 log2 SJ/FSJ), HEM14 (0.11 log2 SJ/FSJ), HEM15 (0.15 log2 SJ/FSJ) and HEM25 (0.51 log2 SJ/FSJ). 
Hemes are prosthetic groups of cytochromes and some oxygen-binding proteins. Considering that oxygen is required for its synthesis, heme plays a central role in oxygen-mediated gene expression in yeast [40]. Several transcription factors are involved in this mechanism: Hap1p, Hap2/3/4/5p, Rox1p and Mot3p. Interestingly, HAP4, ROX1 and MOT3 were significantly induced in SJ. HAP1, which is constitutively transcriptionally active, was found to be not differentially expressed in SJ and FSJ media. Hap1p (heme activated protein) activates the transcription of many aerobic genes involved in the aerobic respiratory chain (such as CYC1 $=1.56 \log 2 \mathrm{SJ} / \mathrm{FSJ}$, COX4 $=0.48 \log 2 \mathrm{SJ} / \mathrm{FSJ}$, COX5 $a=0.63 \log 2 \mathrm{SJ} / \mathrm{FSJ}, \mathrm{COX} 8=0.66 \log 2 \mathrm{SJ} / \mathrm{FSJ}, \mathrm{CYT1}=1.02 \log 2 \mathrm{SJ} / \mathrm{FSJ})$, in sterol synthesis (HMG1 $=1.80 \log 2 \mathrm{SJ} / \mathrm{FSJ}$, ERG1, ERG5, ERG11,ERG2,ERG29, ERG6, ERG26) as well as the transcription factor ROX1. In the cell nucleus, Rox1p in combination with Mot3p forms a complex with Ssn6p/Tup1p, which results in the repression of hypoxic genes [41]. Rox1p and Mot3p may also function independently of each other [42]. In particular, Mot3p inhibits Ecm22p, but not Upc2p.

In our experimental conditions, the absence of lipid nutrients induced the expression of both hypoxic (through Upc2p) and aerobic (through the activator Hap1p and the repressors Rox1p and Mot3p) genes. Even though this could be seen as a contradictory behavior, it should be noted that the transition from aerobiosis to anaerobiosis is a gradual process in which microbial cells pass several stages of adaptation. In the absence of oxygen, the concentrations of heme and sterols decrease gradually, via their dilution in the process of cell division. Also, aerobic and hypoxic genes in most cases are regulated autonomously from each other to allow a fine-tune adaptation to various oxygen concentrations. In particular, the activation of the transcription of genes involved in sterol synthesis mediated by Upc2p in response to the decrease in sterol concentration is independent of Hap1p, Rox1p, and the level or presence of heme [33,34]. Also PAU gene induction is Rox1p independent [39], and data from previous studies have suggested that the hypoxic induction of $P A U$ genes is Hap1p independent as well [43].

Analysis of functional categories enrichment showed that a lack of lipid nutrients induced a stress response in yeast cells. Besides the upregulation of the already cited PAU genes, many genes encoding for Heat Shock Proteins (HSPs) were also induced in SJ. HSPS are required for the folding and maintenance of newly translated proteins, the refolding of misfolded proteins, and the disassembly of protein aggregates [6]. Considering that ethanol accumulation leads to the denaturation of cellular proteins, the induction of HSPs is a well-known stress response mechanism during alcoholic fermentation [44]. Specific activities of HSPs have been reported. While Hsp70p unselectively recognize unfolded or misfolded proteins, the Hsp90s (HSP82 and HSC82) activity is specifically targeted to the stabilization of kinases and transcription factors such as Swe1p, Gcn2p, and Hap1p [6]. Hsp104p and Hsp12p have been shown to directly influence yeast tolerance to ethanol through disaggregation of denaturated proteins and protection of membrane integrity, respectively [45]. Thus considering, the significantly higher induction of HSPs genes, particularly HSP12, was expected as cells growing in SJ were unable to counteract ethanol stress by increasing the ergosterol content in cellular membranes [46].

Oxidative damage to cell structures is another well-known stress experienced by yeast growing in hypoxic conditions, particularly in absence of lipid supplementation. Specifically, our previous results showed that Reactive Oxygen Species (ROS) increased in M25 and EC1118 during fermentation in SJ medium starting from the third day after the inoculum [4]. Under hypoxic conditions, yeast cells modify the mitochondrial respiratory chain to limit ROS production. A key enzyme in this process is the cytochrome c oxidase (COX) which regulates the electron flow through the respiratory chain. S. cerevisiae contains two oxygen-regulated subunits 5 of COX: COX5a and COX5b. Similarly, the cytochrome c exists in two isoforms encoded by CYC1 and CYC7 [47]. COX5a and CYC1 are expressed in normoxia whereas $C O X 5 b$ and $C Y C 7$ are expressed under hypoxia [48]. Interestingly, we found that in absence of lipid supplementation, the two strains induced the transcription of the normoxic subunits $C O X 5 a$ and $C Y C 1$, suggesting an inadequate adaptation to the hypoxic conditions of growth which could be the cause of the observed ROS accumulation [4]. In addition, significant levels of ROS are also produced in hypoxia through $\mathrm{NAD}(\mathrm{P}) \mathrm{H}$-dependent pathways [49]. Notwithstanding ROS 
accumulation, genes differentially regulated in the two media by the transcription factor Yap1p were mainly involved in the cytoplasmatic translation (synthesis of ribosomes, purines, amino-acid transport, etc.) and not in the oxidative stress response. Particularly, the glutaredoxin system (GSH1, GLR1), superoxide dismutase (SOD1, SOD2), catalase activity (CAT1, CTT1), glutathione peroxidase (GPX2), and thiol-specific peroxidases (TSA1, AHP1) were not differentially expressed in SJ as compared to FSJ. In accordance, neither M25 nor EC1118 showed appreciable catalase (CAT) activities in SJ [4]. The repression of these ROS scavenging systems in SJ is even more surprisingly given that the addition of oleic acid and ergosterol in FSJ decreased intracellular ROS levels and oxidative damage in M25 and EC1118 [24].

The implementation of a full experimental design allowed us to identify not only the common response to yeast growth in SJ, but also to detect the genes that were differentially expressed in the two strains. Considering that EC1118 and M25 displayed a different fermentative behavior, these genes could reveal the mechanism involved in yeast adaptation to the fermentation in absence of lipid supplementation. Of particular interest are the "fungal-type cell wall" and "integral component of plasma membrane" terms in the Gene Ontology (GO) knowledgebase that comprise 24 and 18 ORFs, respectively, differentially expressed in the two strains. This suggests an important role of these subcellular components in the adaptation to the growth in absence of lipid supplementation.

The in-depth analysis showed that the "fungal-type cell wall" GO term contains 11 PAU genes, 5 TIP/TIR genes as well as CRH1, GAS1, NCW2, PST1, SRL1, SSA1 and TOS6. Regarding PAU genes, only PAU1 and to a larger extent PAU7, were induced more in EC1118 than in M25, while the others showed an opposite behavior. Interestingly, PAU7 was the only PAU gene, among the 19 identified in this study, with an internal chromosomic position. Proteins encoded by CHR1 (chitin transglycosylase) and GAS1 (Beta-1,3-glucanosyltransferase) are involved in cell wall assembly. NCW2, PST1 and SRL1 encode cell wall proteins associated with cell wall stresses. Of interest is the strong repression of TOS6 in M25. TOS6 encodes a glycosylphosphatidylinositol-dependent cell wall protein whose expression is decreased in response to ergosterol perturbation, suggesting a higher impact of ergosterol deprivation in M25. The importance of mannoproteins, particularly the TIR genes in yeast adaptation to stressful conditions has been well documented. Induction of TIR genes has been related to hypoxia, high pressure and low temperature conditions [36,50]. It was also observed that a wine strain which was improved in its ability to grow at low temperatures through evolutionary engineering overexpressed TIR1, TIR4 and TIR3 [51]. In addition, the overexpression of TIP1 improved yeast fermentation activity at low temperatures [52]. It has been postulated that the induction of TIP/TIR genes allow yeast cells to adapt to the reduced membrane fluidity caused by the aforementioned stress factors [36]. In accordance with the importance of sterol and unsaturated fatty acids in regulating membrane fluidity, the induction of TIR genes by Upc2p and Ecm22p occurs in response to sterol depletion [34]. In this context, the downregulation of TIP1, TIR1, TIR2, TIR3 and TIR4 in M25 growing in SJ could severely affect its ability to adapt to the absence of lipids. On the contrary, EC1118 showed not significant changes in TIP1 and TIR1 and an induction of TIR2, TIR3 and TIR4 in SJ.

The ORFs represented in the "integral component of plasma membrane" GO term were associated with the transport of sugars (HXT1, HT3, HXT4, HXT5, HXT7), nitrogen sources (MEP1,OPT1, DIP5, MUP3, DUR3), cadmium (PCA1), sulphate (SUL2) and copper (CTR3) inside the cell. Of interest are the hexose transporters HXT1, HXT3 and HXT6 that showed an opposite behavior in M25 (repressed) and EC1118 (upregulated) during yeast growth in SJ. These genes encode for low affinity glucose transporters induced at high sugar concentrations [53] and thus essential in the fermentation of SJ and FSJ ( $200 \mathrm{~g} / \mathrm{L}$ glucose). It could be postulated that the repression of these transporters in M25 is reducing the amount of intra-cellular glucose that is used by this strain, thus causing the subsequent stuck/sluggish fermentation.

Finally, the annotation cluster with the higher statistical significance was related to the "methionine biosynthetic process" GO term. All of the ORFs included in this term showed a higher repression in M25 than in EC1118, suggesting a reduced methionine synthesis in the former strain. Methionine acts 
as a ROS scavenger and protects cells from oxidative stress [54]. Indeed, sulfur in methionine is a direct target of ROS, as it can be oxidized to sulfoxide. In addition, it has been shown that protein expressed at sites of ROS production, such as in the mitochondrial respiratory chain are enriched in methionine [55]. Thus, in M25 growing in SJ, the repression of genes involved in methionine biosynthesis together with the already discussed lack of induction of oxidative stress responsive genes, could explain the accumulation of ROS and the inability to complete the fermentation in medium lacking lipid nutrition. It has been observed that the addition of $1 \mathrm{~g} / \mathrm{L}$ of acetaldehyde to S. cerevisiae cells growing in YEPD induced the expression of genes involved in sulfate uptake and homocysteine synthesis (SUL2, MET2, MET3, MET14, MET16, MET10, MET25) [56]. Thus, it could be hypothesized that the observed differences in the expression of genes of the sulfur metabolism in EC1118 and M25, could be due to differences in the levels of acetaldehyde produced by the two strains in SJ. In this respect, previous works have shown that during the fermentation of wine-based media, M25 and EC1118 produced $65.00 \mathrm{mg} / \mathrm{L}$ and $23.40 \mathrm{mg} / \mathrm{L}$ of acetaldehyde, respectively $[57,58]$. Notwithstanding the relevant differences in the conditions reported by [56] and those in this work, the aforementioned hypothesis deserves subsequent evaluation.

\section{Conclusions}

A genome-wide analysis of two wine yeast strains with different fermentative behaviors revealed common and strain-specific responses. Common responses observed in the absence of lipids regarded the induction of the expression of genes involved in ergosterol biosynthesis, as well as genes, such as those in seripauperin and heat shock protein multigene families, related to the adaptation to wine-making stresses. The activation of some aerobic genes, particularly those involved in the mitochondrial respiratory chain, could explain previous results showing ROS accumulation in these strains when growing in absence of lipid supplementation. However, genes directly involved in the oxidative stress response were not differentially expressed in the two tested conditions. In this context, the higher inhibition of the methionine biosynthetic process in M25, which underwent sluggish fermentation, suggested an important role of the sulfur-mediated ROS scavenging system in SJ. In addition, M25 was characterized by the downregulation of the mannoprotein encoding genes TIP1, TIR1, TIR2, TIR3 and TIR4, previously associated with yeast adaptation to stress conditions such as low temperatures, high ethanol, and hypoxia. In conclusion, the results obtained in this work provide a valuable dataset to further investigate the mechanisms involved in yeast adaptation during growth in the absence of lipid supplementation and to assist in industrial strain selection.

Supplementary Materials: The following are available online at http://www.mdpi.com/2311-5637/5/3/57/s1, Table S1: ORFs differentially expressed in EC1118 and M25 during fermentation in absence of oleic acid and ergosterol.

Author Contributions: Conceptualization, G.Z., H.J.J.v.V. and M.B.; Data curation, G.Z.; Formal analysis, G.Z. and I.M.; Investigation, G.Z. and S.Z.; Methodology, G.Z.; Project administration, H.J.J.v.V. and M.B.; Resources, H.J.J.v.V. and M.B.; Validation, G.Z., I.M. and S.Z.; Visualization, G.Z. and I.M.; Writing-original draft, G.Z.; Writing-review \& editing, H.J.J.v.V., I.M., S.Z. and M.B.

Funding: G.Z. research grant was founded by the Sardinia Regional Government (Regional Operational Program of the European Social Fund (ROP ESF) 2014-2020-Priority axis 3 "Education and training"; Thematic objective: 10; Investment Priority: 10ii; Specific Objective: 10.5; Action of the Partnership Agreement: 10.5.12-C.U.P. J86C18000270002).

Conflicts of Interest: The authors declare no conflict of interest.

\section{References}

1. Hohmann, S. An integrated view on a eukaryotic osmoregulation system. Curr. Genet. 2015, 61, 373-382. [CrossRef] [PubMed]

2. Cutler, N.S.; Pan, X.; Heitman, J.; Cardenas, M.E. The TOR signal transduction cascade controls cellular differentiation in response to nutrients. Mol. Biol. Cell 2001, 12, 4103-4113. [CrossRef] [PubMed] 
3. Zara, G.; Budroni, M.; Mannazzu, I.; Zara, S. Air-liquid biofilm formation is dependent on ammonium depletion in a Saccharomyces cerevisiae flor strain. Yeast 2011, 28, 809-814. [CrossRef] [PubMed]

4. Landolfo, S.; Politi, H.; Angelozzi, D.; Mannazzu, I. ROS accumulation and oxidative damage to cell structures in Saccharomyces cerevisiae wine strains during fermentation of high-sugar-containing medium. Biochim. Biophys. Acta 2008, 1780, 892-898. [CrossRef] [PubMed]

5. Morano, K.A.; Grant, C.M.; Moye-Rowley, W.S. The response to heat shock and oxidative stress in Saccharomyces cerevisiae. Genetics 2012, 190, 1157-1195. [CrossRef] [PubMed]

6. Verghese, J.; Abrams, J.; Wang, Y.; Morano, K.A. Biology of the heat shock response and protein chaperones: Budding yeast (Saccharomyces cerevisiae) as a model system. Microbiol. Mol. Biol. Rev. MMBR 2012, 76, 115-158. [CrossRef]

7. Sahara, T.; Goda, T.; Ohgiya, S. Comprehensive expression analysis of time-dependent genetic responses in yeast cells to low temperature. J. Biol. Chem. 2002, 277, 50015-50021. [CrossRef]

8. Heinisch, J.J.; Rodicio, R. Stress responses in wine yeast. In Biology of Microorganisms on Grapes, in Must and in Wine; König, H., Unden, G., Fröhlich, J., Eds.; Springer International Publishing: Cham, Switzerland, 2017; pp. 377-395. ISBN 978-3-319-60021-5.

9. Henderson, C.M.; Block, D.E. Examining the Role of Membrane Lipid Composition in Determining the Ethanol Tolerance of Saccharomyces cerevisiae. Appl. Environ. Microbiol. 2014, 80, 2966-2972. [CrossRef]

10. Klug, L.; Daum, G. Yeast lipid metabolism at a glance. FEMS Yeast Res. 2014, 14, 369-388. [CrossRef]

11. Luparia, V.; Soubeyrand, V.; Berges, T.; Julien, A.; Salmon, J.-M. Assimilation of grape phytosterols by Saccharomyces cerevisiae and their impact on enological fermentations. Appl. Microbiol. Biotechnol. 2004, 65, 25-32. [CrossRef]

12. Duan, L.L.; Shi, Y.; Jiang, R.; Yang, Q.; Wang, Y.Q.; Liu, P.T.; Duan, C.Q.; Yan, G.L. Effects of adding unsaturated fatty acids on fatty acid composition of Saccharomyces cerevisiae and major volatile compounds in wine. S. Afr. J. Enol. Vitic. 2015, 36, 285-295. [CrossRef]

13. Valero, E.; Millan, M.C.; Mauricio, J.C.; Ortega, J.M. Effect of grape skin maceration on sterol, phospholipid, and fatty acid contents of Saccharomyces cerevisiae during alcoholic fermentation. Am. J. Enol. Vitic. 1998, 49, 119-124.

14. Aceituno, F.F.; Orellana, M.; Torres, J.; Mendoza, S.; Slater, A.W.; Melo, F.; Agosin, E. Oxygen response of the wine yeast Saccharomyces cerevisiae EC1118 grown under carbon-sufficient, nitrogen-limited enological conditions. Appl. Environ. Microbiol. 2012, 78, 8340-8352. [CrossRef] [PubMed]

15. Zara, G.; Bardi, L.; Belviso, S.; Farris, G.A.; Zara, S.; Budroni, M. Correlation between cell lipid content, gene expression and fermentative behaviour of two Saccharomyces cerevisiae wine strains. J. Appl. Microbiol. 2008, 104, 906-914. [CrossRef] [PubMed]

16. Bely, M.; Sablayrolles, J.M.; Barre, P. Description of alcoholic fermentation kinetics: Its variability and significance. Am. J. Enol. Vitic. 1990, 41, 319-324.

17. Ausubel, F.M.; Brent, R.; Kingston, R.E.; Moore, D.D.; Seidman, J.G.; Smith, J.A.; Struhl, K. Hot-phenol RNA extraction. In Current Protocols in Molecular Biology; John Wiley and Sons Inc.: New York, NY, USA, 1995.

18. Causton, H.C.; Ren, B.; Koh, S.S.; Harbison, C.T.; Kanin, E.; Jennings, E.G.; Lee, T.I.; True, H.L.; Lander, E.S.; Young, R.A. Remodeling of yeast genome expression in response to environmental changes. Mol. Biol. Cell 2001, 12, 323-337. [CrossRef]

19. Jelinsky, S.A.; Samson, L.D. Global response of Saccharomyces cerevisiae to an alkylating agent. Proc. Natl. Acad. Sci. USA 1999, 96, 1486-1491. [CrossRef]

20. Edgar, R.; Domrachev, M.; Lash, A.E. Gene Expression Omnibus: NCBI gene expression and hybridization array data repository. Nucleic Acids Res. 2002, 30, 207-210. [CrossRef]

21. Benjamini, Y.; Hochberg, Y. Controlling the False Discovery Rate: A practical and powerful approach to multiple testing. J. R. Stat. Soc. Ser. B Methodol. 1995, 57, 289-300. [CrossRef]

22. Huang, D.W.; Sherman, B.T.; Lempicki, R.A. Systematic and integrative analysis of large gene lists using DAVID bioinformatics resources. Nat. Protoc. 2009, 4, 44-57. [CrossRef]

23. Teixeira, M.C.; Monteiro, P.; Jain, P.; Tenreiro, S.; Fernandes, A.R.; Mira, N.P.; Alenquer, M.; Freitas, A.T.; Oliveira, A.L.; Sá-Correia, I. The YEASTRACT database: A tool for the analysis of transcription regulatory associations in Saccharomyces cerevisiae. Nucleic Acids Res. 2006, 34, D446-D451. [CrossRef] [PubMed] 
24. Landolfo, S.; Zara, G.; Zara, S.; Budroni, M.; Ciani, M.; Mannazzu, I. Oleic acid and ergosterol supplementation mitigates oxidative stress in wine strains of Saccharomyces cerevisiae. Int. J. Food Microbiol. 2010, 141, 229-235. [CrossRef] [PubMed]

25. Bisson, L.F. Stuck and sluggish fermentations. Am. J. Enol. Vitic. 1999, 50, 107-119.

26. Zara, G.; Angelozzi, D.; Belviso, S.; Bardi, L.; Goffrini, P.; Lodi, T.; Budroni, M.; Mannazzu, I. Oxygen is required to restore flor strain viability and lipid biosynthesis under fermentative conditions. FEMS Yeast Res. 2009, 9, 217-225. [CrossRef] [PubMed]

27. Tesnière, C.; Delobel, P.; Pradal, M.; Blondin, B. Impact of nutrient imbalance on wine alcoholic fermentations: Nitrogen excess enhances yeast cell death in lipid-limited must. PLoS ONE 2013, 8, e61645. [CrossRef] [PubMed]

28. Kennedy, M.A.; Barbuch, R.; Bard, M. Transcriptional regulation of the squalene synthase gene (ERG9) in the yeast Saccharomyces cerevisiae. Biochim. Biophys. Acta 1999, 1445, 110-122. [CrossRef]

29. Hickman, M.J.; Spatt, D.; Winston, F. The Hog1 mitogen-activated protein kinase mediates a hypoxic response in Saccharomyces cerevisiae. Genetics 2011, 188, 325-338. [CrossRef] [PubMed]

30. Davies, B.S.J.; Wang, H.S.; Rine, J. Dual activators of the sterol biosynthetic pathway of Saccharomyces cerevisiae: Similar activation/regulatory domains but different response mechanisms. Mol. Cell. Biol. 2005, 25, 7375-7385. [CrossRef]

31. Hughes, A.L.; Todd, B.L.; Espenshade, P.J. SREBP pathway responds to sterols and functions as an oxygen sensor in fission yeast. Cell 2005, 120, 831-842. [CrossRef]

32. Wilcox, L.J.; Balderes, D.A.; Wharton, B.; Tinkelenberg, A.H.; Rao, G.; Sturley, S.L. Transcriptional profiling identifies two members of the ATP-binding cassette transporter superfamily required for sterol uptake in yeast. J. Biol. Chem. 2002, 277, 32466-32472. [CrossRef]

33. Davies, B.S.J.; Rine, J. A role for sterol levels in oxygen sensing in Saccharomyces cerevisiae. Genetics 2006, 174, 191-201. [CrossRef] [PubMed]

34. Todd, B.L.; Stewart, E.V.; Burg, J.S.; Hughes, A.L.; Espenshade, P.J. Sterol regulatory element binding protein is a principal regulator of anaerobic gene expression in fission yeast. Mol. Cell. Biol. 2006, 26, 2817-2831. [CrossRef] [PubMed]

35. Luo, Z.; van Vuuren, H.J.J. Functional analyses of PAU genes in Saccharomyces cerevisiae. Microbiology 2009, 155, 4036-4049. [CrossRef] [PubMed]

36. Abramova, N.E.; Cohen, B.D.; Sertil, O.; Kapoor, R.; Davies, K.J.; Lowry, C.V. Regulatory mechanisms controlling expression of the DAN/TIR mannoprotein genes during anaerobic remodeling of the cell wall in Saccharomyces cerevisiae. Genetics 2001, 157, 1169-1177. [PubMed]

37. Rossignol, T.; Dulau, L.; Julien, A.; Blondin, B. Genome-wide monitoring of wine yeast gene expression during alcoholic fermentation. Yeast 2003, 20, 1369-1385. [CrossRef] [PubMed]

38. Marks, V.D.; Ho Sui, S.J.; Erasmus, D.; van der Merwe, G.K.; Brumm, J.; Wasserman, W.W.; Bryan, J.; van Vuuren, H.J.J. Dynamics of the yeast transcriptome during wine fermentation reveals a novel fermentation stress response. FEMS Yeast Res. 2008, 8, 35-52. [CrossRef] [PubMed]

39. Rachidi, N.; Martinez, M.J.; Barre, P.; Blondin, B. Saccharomyces cerevisiae PAU genes are induced by anaerobiosis. Mol. Microbiol. 2000, 35, 1421-1430. [CrossRef] [PubMed]

40. Plakunov, V.K.; Shelemekh, O.V. Mechanisms of oxygen regulation in microorganisms. Microbiology 2009, 78, 535-546. [CrossRef]

41. Klinkenberg, L.G.; Mennella, T.A.; Luetkenhaus, K.; Zitomer, R.S. Combinatorial repression of the hypoxic genes of Saccharomyces cerevisiae by DNA binding proteins Rox1 and Mot3. Eukaryot. Cell 2005, 4, 649-660. [CrossRef]

42. Sertil, O.; Kapoor, R.; Cohen, B.D.; Abramova, N.; Lowry, C.V. Synergistic repression of anaerobic genes by Mot3 and Rox1 in Saccharomyces cerevisiae. Nucleic Acids Res. 2003, 31, 5831-5837. [CrossRef]

43. Hickman, M.J.; Winston, F. Heme levels switch the function of Hap1 of Saccharomyces cerevisiae between transcriptional activator and transcriptional repressor. Mol. Cell. Biol. 2007, 27, 7414-7424. [CrossRef]

44. Auesukaree, C. Molecular mechanisms of the yeast adaptive response and tolerance to stresses encountered during ethanol fermentation. J. Biosci. Bioeng. 2017, 124, 133-142. [CrossRef]

45. Sales, K.; Brandt, W.; Rumbak, E.; Lindsey, G. The LEA-like protein HSP12 in Saccharomyces cerevisiae has a plasma membrane location and protects membranes against desiccation and ethanol-induced stress. Biochim. Biophys. Acta 2000, 1463, 267-278. [CrossRef] 
46. Shobayashi, M.; Mitsueda, S.; Ago, M.; Fujii, T.; Iwashita, K.; Iefuji, H. Effects of culture conditions on ergosterol biosynthesis by Saccharomyces cerevisiae. Biosci. Biotechnol. Biochem. 2005, 69, 2381-2388. [CrossRef]

47. Burke, P.V.; Raitt, D.C.; Allen, L.A.; Kellogg, E.A.; Poyton, R.O. Effects of oxygen concentration on the expression of cytochrome $\mathrm{c}$ and cytochrome c oxidase genes in yeast. J. Biol. Chem. 1997, 272, 14705-14712. [CrossRef]

48. Liu, J.; Barrientos, A. Transcriptional regulation of yeast oxidative phosphorylation hypoxic genes by oxidative stress. Antioxid. Redox Signal. 2013, 19, 1916-1927. [CrossRef]

49. Rosenfeld, E.; Beauvoit, B.; Blondin, B.; Salmon, J.-M. Oxygen consumption by anaerobic Saccharomyces cerevisiae under enological conditions: Effect on fermentation kinetics. Appl. Environ. Microbiol. 2003, 69, 113-121. [CrossRef]

50. Abe, F. Induction of DAN/TIR yeast cell wall mannoprotein genes in response to high hydrostatic pressure and low temperature. FEBS Lett. 2007, 581, 4993-4998. [CrossRef]

51. López-Malo, M.; García-Rios, E.; Melgar, B.; Sanchez, M.R.; Dunham, M.J.; Guillamón, J.M. Evolutionary engineering of a wine yeast strain revealed a key role of inositol and mannoprotein metabolism during low-temperature fermentation. BMC Genom. 2015, 16, 537.

52. Chiva, R.; López-Malo, M.; Salvadó, Z.; Mas, A.; Guillamón, J.M. Analysis of low temperature-induced genes (LTIG) in wine yeast during alcoholic fermentation. FEMS Yeast Res. 2012, 12, 831-843. [CrossRef]

53. Kwast, K.E.; Burke, P.V.; Poyton, R.O. Oxygen sensing and the transcriptional regulation of oxygen-responsive genes in yeast. J. Exp. Biol. 1998, 201, 1177-1195. [PubMed]

54. Luo, S.; Levine, R.L. Methionine in proteins defends against oxidative stress. FASEB J. Off. Publ. Fed. Am. Soc. Exp. Biol. 2009, 23, 464-472. [CrossRef] [PubMed]

55. Schindeldecker, M.; Moosmann, B. Protein-borne methionine residues as structural antioxidants in mitochondria. Amino Acids 2015, 47, 1421-1432. [CrossRef] [PubMed]

56. Aranda, A.; del Olmo, M. Exposure of Saccharomyces cerevisiae to acetaldehyde induces sulfur amino acid metabolism and polyamine transporter genes, which depend on Met4p and Haa1p transcription factors, respectively. Appl. Environ. Microbiol. 2004, 70, 1913-1922. [CrossRef] [PubMed]

57. Zara, G.; Mannazzu, I.; Sanna, M.L.; Orro, D.; Farris, G.A.; Budroni, M. Exploitation of the semi-homothallic life cycle of Saccharomyces cerevisiae for the development of breeding strategies. FEMS Yeast Res. 2008, 8, 1147-1154. [CrossRef]

58. Li, E.; de Orduña, R.M. Evaluation of the acetaldehyde production and degradation potential of 26 enological Saccharomyces and non-Saccharomyces yeast strains in a resting cell model system. J. Ind. Microbiol. Biotechnol. 2011, 38, 1391-1398. [CrossRef] [PubMed]

(C) 2019 by the authors. Licensee MDPI, Basel, Switzerland. This article is an open access article distributed under the terms and conditions of the Creative Commons Attribution (CC BY) license (http://creativecommons.org/licenses/by/4.0/). 